\title{
Umbilical and Middle Cerebral Artery Doppler Indices at Late Third Trimester in the Prediction of Perinatal Outcome in Growth Restricted Fetuses Hossam Hassan Mahmoud El Ktatny, Khaled Mohamed Ahmed Mohamed, Mostafa Amman Ahmed Mohamed*
}

Department of Obstetrics and Gynecology, Faculty of Medicine, Al-Azhar University (Assiut), Assiut, Egypt

*Corresponding author: Mostafa Amman Ahmed Mohamed, Mobile: (+20) 01099870783, E-Mail: mostafa_aman2015@yahoo.com

\begin{abstract}
Background: Intrauterine growth restriction (IUGR) is implied to those fetuses who do not achieve their genetically determined potential size. IUGR being a major complication of pregnancy may result in significant morbidity and mortality. Objective: To evaluate the potential value of (CPR) measured at 34-37 weeks' gestation in predicting the perinatal outcome of pregnancies with FGR.

Patients and Methods: A prospective observational study was conducted in Al-Helal Health Insurance Hospital from October 2018 to September 2019. The target population for this study were pregnant females with gestational age between 34- 37 weeks and with biometrically suspected intrauterine growth-restricted fetuses attending the hospital for antenatal care, and are fulfilling the inclusion and exclusion criteria. Doppler ultrasound evaluation of Umbilical and Middle cerebral arteries was performed and CPR was calculated. At 34-37 weeks' gestation. Patients characteristics, intrapartum, and neonatal outcomes were recorded. The main outcomes required urgent Cesarean section (CS) due to intrapartum fetal compromise (IFC), 5-minute Apgar score below 7, neonatal death, and admission at neonatal intensive care unit (NICU).

Results: A total of 40 women participated in this study with an unfavorable outcome in $20 \%$ of newborns. Abnormal CRP was present in 11 cases and was associated with a higher risk of adverse outcomes in terms of the need for urgent CS, lower fetal weight, 5-minute Apgar score under 7, and neonatal death and NICU admission > 10 days., and the diagnostic accuracy of CRP was superior to either umbilical artery pulsitivity index (UA-PI) or middle cerebral artery pulsitivity index (MCA-PI) alone.
\end{abstract}

Conclusion: CPR was more effective, with higher specificity and diagnostic accuracy, in predicting perinatal outcomes compared with the individual Doppler parameters of MCA and UA.

Keywords: Cerebroplacental ratio, fetal growth restriction, Doppler indices, perinatal outcome.

\section{INTRODUCTION}

Intrauterine growth restriction (IUGR) is implied to those fetuses who do not achieve their genetically determined potential size. IUGR being a major complication of pregnancy may result in significant morbidity and mortality, hence timely diagnosis is of utmost importance. The widely accepted definition of IUGR is a fetus whose estimated fetal weight is below the 10th percentile for its gestational age. The growth of the fetus is multifactorial depending upon the mother. Both fetal and maternal blood flow has to be adequate for normal placental function and subsequently fetal growth. Any compromise in the fetoplacental circulation results in placental insufficiency which further promotes compensatory changes in fetal circulation ${ }^{(1)}$.

For assessment of fetal oxygenation, we use Doppler assessment of impedance to flow in the UA, fetal MCA, and the ratio of PI in these vessels, or CPR. The incidence of impaired placentation and adverse perinatal events is higher in SGA than in appropriatefor-gestational-age (AGA) fetuses with a birth weight above the 10th percentile ${ }^{(2)}$. Antenatal diagnosis of fetal growth restriction (FGR) depends on the sonographic estimation of certain anthropometric measures ${ }^{(\mathbf{3})}$.

The use of doppler velocimetry of umbilical artery (UA) and middle cerebral artery (MCA) in highrisk pregnancies, including FGR, has been reported to decrease perinatal morbidity and mortality. Cerebroplacental ratio (CPR) is another Doppler index that represents cerebral centralization of fetal blood flow. CPR is calculated by dividing the doppler index (pulsatility index [PI], resistance index, or systolic/diastolic ratio) of the MCA by that of the $\mathrm{UA}^{(4)}$. The present work aimed to: Evaluate the potential value of CPR measured at 34-37 weeks' gestation in predicting the perinatal outcome of pregnancies with FGR.

\section{PATIENTS AND METHODS}

Patients: This was a prospective observational study conducted at Al-Helal Health Insurance Hospital in Sohag Governorate (Egypt) from October 2018 to the end of September 2019. The target population for this study was pregnant females with gestational age between 34- 37 weeks and with biometrically suspected 
intrauterine growth-restricted fetuses attending the hospital for antenatal care and are fulfilling the inclusion and exclusion criteria.

Inclusion criteria: Maternal age between 18- 35 years, gestational age between 34-37 weeks by dating or 1sttrimester ultrasound, singleton pregnancies suspicious for IUGR, and chronic maternal illness (as chronic hypertension, pre-eclampsia, diabetes mellitus. etc.)

.Exclusion criteria: Multi-fetal pregnancies, congenital fetal malformations, chromosomal abnormalities known before labor and delivery, and preterm premature rupture of membrane.

The study included 40 pregnant females with gestational age between 34- 37 weeks, and with biometrically suspected intrauterine growth-restricted fetuses. Biometric parameters suggestive of IUGR included in the study were fetal weight, head circumference, biparietal diameter, abdominal circumference, femur length, amniotic fluid index, and placental grading.

Ethical consideration

The present study was approved by the Research Ethics Committee of Faculty of Medicine, Al-Azhar University (Assiut).

Informed consent was obtained from all included pregnant women for their participation.

The following was performed for all pregnant females included in this study:

- Full history (demographic data and personal history, detailed history of general health condition, and chronic or current diseases).

- Recording of maternal characteristics and medical history.

- General and local examination.

- Estimation of fetal size through trans-abdominal ultrasound measurement of fetal head circumference, abdominal circumference, and femur length.

- Doppler ultrasound evaluation of Umbilical and Middle cerebral arteries was performed and CPR was calculated. Doppler study was considered abnormal if UAD PI > 95th percentile for gestational age, MCD PI < 5th percentile for gestational age, CPR < 1.08 (Singh et al., 2018).

We followed enrolled cases for mode and indication of delivery, birth weight, and neonatal outcome. The outcomes of this study were the need for urgent Cesarean section (CS) due to intrapartum fetal compromise (IFC), low birth weight $(<5$ th and $<10$ th centile), 5-minute Apgar score $\leq 7$, need and duration of admission at neonatal intensive care unit (NICU), and neonatal death.

\section{Statistical analysis}

The collected data were analyzed using the Statistical Package for the Social Sciences (SPSS) program for windows version 20 (SPSS Inc., Chicago, IL, USA). The data were presented as number and percentage for the qualitative data, mean \pm standard deviation (SD) for normally-distributed quantitative data, and median with interquartile range (IQR) for the quantitative data with the non-parametric distribution. Pearson Chi-square test was used to compare percentages between qualitative variables. The student t-test was used to compare means between two independent groups for parametric data (normally distributed), and the Mann-Witney test was used instead of the Student t-test to compare medians between two independent groups in cases of non-parametric distribution of data. Sensitivity statistics were used to estimate the accuracy of different screening methods in the prediction of neonatal outcome. P-values $<0.05$ and $<0.01$ were considered significant and highly significant, respectively.

\section{RESULTS}

Table (1): Characteristics and perinatal outcome of study participants

\begin{tabular}{|l|l|}
\hline \multicolumn{1}{|c|}{ Variable } & \multicolumn{1}{|c|}{ Value } \\
\hline $\begin{array}{l}\text { Maternal age } \\
\text { (mean } \pm \text { SD) in years }\end{array}$ & $26.25 \pm 4.37$ \\
\hline $\begin{array}{l}\text { Gestational age } \\
\text { mean } \pm \text { SD) in weeks }\end{array}$ & $35.95 \pm 1.10$ \\
\hline Residence: No. (\%) & \\
Rural & $21(52.50 \%)$ \\
Urban & $19(47.50 \%)$ \\
\hline Parity: No. (\%) & $13(32.50 \%)$ \\
Primigravida & $27(67.50 \%)$ \\
\hline Multigravida & $16(40.00 \%)$ \\
\hline $\begin{array}{l}\text { Mode of delivery: No. (\%) } \\
\text { Normal }\end{array}$ & $19(47.5 \%)$ \\
Elective Cesarean section & $5(12.5 \%)$ \\
\hline Urgent Cesarean section & $2054 \pm 347.20$ \\
\hline Fetal weight (mean \pm SD) in gm & $5(12.50 \%)$ \\
\hline 5-min Apgar score below 7: & \\
No. (\%) & $32(80.00 \%)$ \\
\hline Neonatal outcome: No. (\%) & $2(5.00 \%)$ \\
Normal & $3(7.50 \%)$ \\
Death & $3(7.50 \%)$ \\
\hline NICU admission > 10 days & \\
NICU admission > 10 days & \\
\hline \multicolumn{2}{|l}{ (\%) }
\end{tabular}

The mean age of the pregnant females was $26.25 \pm 4.37$ years; their mean gestational age was $35.95 \pm 1.10$ weeks; their residence was rural in $52.5 \%$ of cases and urban in $47.5 \%$ of cases; $67.5 \%$ of cases were multigravida and $32.5 \%$ of them were primigravida; $60 \%$ of them delivered by CS, of which the CS was elective in $79.17 \%$ of cases and was urgent in $20.83 \%$ of cases whereas $40 \%$ of them delivered normally. The 
mean UAD PI was $1.06 \pm 0.45$ as it ranged from 0.47 to 2.5 and it was normal in $50 \%$ of cases and abnormal in the other $50 \%$. The mean MCD PI was $1.33 \pm 0.38$ as it ranged from 0.71 to 2 and it was abnormal in $52.5 \%$ of cases and normal in $47.5 \%$ of cases (Table 2).

Table (2): Doppler indices of Umbilical Artery (UAD) and Middle Cerebral Artery (MCD)in the study population:

\begin{tabular}{|l|l|c|}
\hline & Variable & $\begin{array}{l}\text { Summary } \\
\text { statistics }\end{array}$ \\
\hline UAD & Mean \pm SD & $1.06 \pm 0.45$ \\
PI & Range & $0.47: 2.5$ \\
\hline UAD & Abnormal & $20(50.00 \%)$ \\
PI & Normal & $20(50.00 \%)$ \\
\hline MCD & Mean \pm SD & $1.33 \pm 0.38$ \\
PI & Range & $0.71: 2$ \\
\hline MCD & Abnormal & $21(52.50 \%)$ \\
PI & Normal & $19(47.50 \%)$ \\
\hline
\end{tabular}

The mean CPR was $1.48 \pm 0.60$ as it ranged from 0.47 to 2.7 and it was normal in $72.5 \%$ of cases and abnormal in $27.5 \%$ of cases (Table 3 ).

Table (3): CPR in the study population:

\begin{tabular}{|l|l|c|}
\hline & Variable & Summary statistics \\
\hline CPR & Mean \pm SD & $1.48 \pm 0.60$ \\
& Range & $0.47: 2.7$ \\
\hline CPR & Abnormal & $11(27.50 \%)$ \\
& Normal & $29(72.50 \%)$ \\
\hline
\end{tabular}

the other side, participants with abnormal CPR had significantly increased incidence of adverse perinatal outcome in terms of the need for urgent CS, lower fetal weight, 5-minute Apgar score under 7, and neonatal death and NICU admission > 10 days. Changes in maternal age, residence, medical history, or parity were not associated with statistically significant changes in neonatal outcomes.

On the other hand, changes in gestational age were associated with statistically significant changes in neonatal outcomes associated with older age. Furthermore, changes in the mode of delivery were associated with very highly statistically significant changes in neonatal outcome with $100 \%$ of normal deliveries being associated with normal neonatal outcome and $15.79 \%$ of elective CS and $100 \%$ of urgent CS deliveries being associated with abnormal neonatal outcome (Table 4).
Table (4): Relation between characteristics of the study population and neonatal outcomes

\begin{tabular}{|l|c|c|c|}
\hline Variable & $\begin{array}{l}\text { Abnormal } \\
\text { outcomes } \\
\text { N=8 }\end{array}$ & $\begin{array}{l}\text { Normal } \\
\text { outcomes } \\
\text { N=32 }\end{array}$ & $\begin{array}{l}\text { P- } \\
\text { value }\end{array}$ \\
\hline $\begin{array}{l}\text { Maternal } \\
\text { age (years) } \\
\text { Mean } \pm \text { SD } \\
\text { Range }\end{array}$ & $\begin{array}{c}26.13 \pm 4.32 \\
22: 34\end{array}$ & $\begin{array}{c}26.28 \pm 4.45 \\
18: 35\end{array}$ & 0.93 \\
\hline $\begin{array}{l}\text { Gestational } \\
\text { age (weeks) }\end{array}$ & $35.25 \pm 1.03$ & $36.13 \pm 1.07$ & $<0.05$ \\
$\begin{array}{l}\text { Mean } \pm \text { SD } \\
\text { Range }\end{array}$ & $34: 36$ & $34: 37$ & \\
\hline $\begin{array}{l}\text { Residence } \\
\text { No (\%) }\end{array}$ & $5(23.81 \%)$ & $16(76.19 \%)$ & 0.53 \\
$\begin{array}{l}\text { Rural } \\
\text { Urban }\end{array}$ & $3(15.79 \%)$ & $16(84.21 \%)$ & \\
\hline $\begin{array}{l}\text { Medical } \\
\text { history No } \\
\text { (\%) }\end{array}$ & $4(16.67 \%)$ & $20(83.33 \%)$ & \\
$\begin{array}{l}\text { No } \\
\text { DM }\end{array}$ & 0 & $7(100 \%)$ & 0.06 \\
$\begin{array}{l}\text { Preeclampsia } \\
\text { Neuropathy }\end{array}$ & $1(100 \%)$ & $5(62.5 \%)$ & \\
\hline $\begin{array}{l}\text { Parity No } \\
\text { (\%) } \\
\text { Primigravida } \\
\text { Multigravida }\end{array}$ & $3(23.08 \%)$ & $10(76.92 \%)$ & 0.74 \\
\hline $\begin{array}{l}\text { Mode of } \\
\text { delivery No } \\
\text { (\%) }\end{array}$ & $5(18.52 \%)$ & $22(81.48 \%)$ & \\
$\begin{array}{l}\text { Normal } \\
\text { Elective CS } \\
\text { Urgent CS }\end{array}$ & $3(15.79 \%)$ & $16(84.21 \%)$ & $<0.0001$ \\
\hline Chang & 0 & \\
\hline
\end{tabular}

Changes in CPR were associated with highly statistically significant changes in neonatal outcomes with higher CPR being associated with normal outcomes. Furthermore, abnormality in CPR was associated with a statistically significant abnormality in the outcome as $89.66 \%$ of those with normal CPR and $54.55 \%$ of those with abnormal CPR had normal outcomes whereas $10.34 \%$ of those with normal CPR and $45.45 \%$ of those with abnormal CPR had an abnormal neonatal outcome. Changes in CPR were associated with highly statistically significant variations in neonatal outcome with $89.66 \%$ of fetuses with normal CPR having normal outcome and $10.34 \%$ of them being admitted for more than 24 days whereas $54.55 \%$ of fetuses with abnormal CPR had normal outcome, $18.18 \%$ of them died and $27.27 \%$ of them were admitted for more than 10 days (Table 5).

Table (5): Relation between CPR and neonatal outcomes \begin{tabular}{l|l} 
Variable & Abnormal outcomes
\end{tabular} 


\begin{tabular}{|c|c|c|c|c|c|}
\hline $\begin{array}{l}\text { CPR } \\
\text { Median } \\
\text { Range } \\
\end{array}$ & \multicolumn{2}{|c|}{$\begin{array}{c}1.60 \\
0.47: 1.86\end{array}$} & \multicolumn{2}{|c|}{$\begin{array}{c}0.99 \\
0.84: 2.7\end{array}$} & 0.008 \\
\hline $\begin{array}{l}\text { CPR: No (\%) } \\
\text { Abnormal } \\
\text { Normal }\end{array}$ & \multicolumn{2}{|c|}{$\begin{array}{l}5(45.45 \%) \\
3(10.34 \%)\end{array}$} & \multicolumn{2}{|c|}{$\begin{array}{c}6(54.55 \%) \\
26(89.66 \%)\end{array}$} & 0.03 \\
\hline \multirow[b]{2}{*}{ CPR } & \multicolumn{4}{|c|}{ Neonatal outcomes No (\%) } & \\
\hline & Normal & Died & $\begin{array}{c}\text { Admitted }>10 \\
\text { days }\end{array}$ & $\begin{array}{c}\text { Admitted }>24 \\
\text { days }\end{array}$ & P-value \\
\hline Normal & $26(89.66 \%)$ & 0 & 0 & $3(10.34 \%)$ & \multirow{2}{*}{0.001} \\
\hline Abnormal & $6(54.55 \%)$ & $2(18.18 \%)$ & $3(27.27 \%)$ & 0 & \\
\hline
\end{tabular}

Table (6): Shows that the sensitivity and specificity of UA Doppler indices in predicting neonatal outcomes are $62.5 \%$ and $53.12 \%$ respectively with a diagnostic accuracy of $55 \%$.

Table (6): Efficacy of Umbilical Artery Doppler indices in predicting neonatal outcomes

\begin{tabular}{|l|c|c|}
\hline \multirow{2}{*}{ UAD PI } & \multicolumn{2}{|c|}{ Outcomes } \\
\cline { 2 - 3 } & Abnormal & Normal \\
\hline Abnormal & $5(25 \%)$ & $15(75 \%)$ \\
\hline Normal & $3(15 \%)$ & $17(85 \%)$ \\
\hline Total & 8 & 32 \\
\hline Measure & Estimate & $95 \%$ Confidence Interval \\
\hline Sensitivity & $62.5 \%$ & $(24.49 \%: 91.48 \%)$ \\
\hline Specificity & $53.12 \%$ & $(34.74 \%: 70.91 \%)$ \\
\hline PPV & $25.00 \%$ & $(14.81 \%: 39.00 \%)$ \\
\hline NPV & $85.00 \%$ & $(68.62 \%: 93.62 \%)$ \\
\hline Diagnostic accuracy & $55.00 \%$ & $(38.49 \%: 70.74 \%)$ \\
\hline
\end{tabular}

Table (7): Shows that the sensitivity and specificity of MCA Doppler indices in predicting neonatal outcomes are $100 \%$ and $59.38 \%$ respectively with a diagnostic accuracy of $67.5 \%$.

Table (7): Efficacy of Middle Cerebral Artery Doppler indices in predicting neonatal outcomes

\begin{tabular}{|l|c|c|}
\hline \multirow{2}{*}{ MCD PI } & \multicolumn{2}{c|}{ Outcome } \\
\cline { 2 - 3 } & Abnormal & Normal \\
\hline Abnormal & $8(38.1 \%)$ & $13(61.9 \%)$ \\
\hline Normal & 0 & $19(100 \%)$ \\
\hline Total & 8 & 32 \\
\hline Measure & Estimate & $95 \%$ Confidence Interval \\
\hline Sensitivity & $100 \%$ & $(63.06 \%: 100 \%)$ \\
\hline Specificity & $59.38 \%$ & $(40.64 \%: 76.30 \%)$ \\
\hline PPV & $38.10 \%$ & $(28.82 \%: 48.33 \%)$ \\
\hline NPV & $100 \%$ & --- \\
\hline Diagnostic accuracy & $67.50 \%$ & $(50.87 \%: 81.43 \%)$ \\
\hline
\end{tabular}

Table (8): Shows that the sensitivity and specificity of CPR in predicting neonatal outcomes are $62.5 \%$ and $81.25 \%$ respectively with a diagnostic accuracy of $77.5 \%$. 


\begin{tabular}{|l|c|c|}
\hline & Abnormal & Normal \\
\hline Abnormal & $5(45.45 \%)$ & $6(54.55 \%)$ \\
\hline Normal & $3(10.34 \%)$ & $26(89.66 \%)$ \\
\hline Total & 8 & 32 \\
\hline Measure & Estimate & $95 \%$ Confidence Interval \\
\hline Sensitivity & $62.50 \%$ & $(24.49 \%: 91.48 \%)$ \\
\hline Specificity & $81.25 \%$ & $(63.56 \%: 92.79 \%)$ \\
\hline PPV & $45.45 \%$ & $(25.32 \%: 67.19 \%)$ \\
\hline NPV & $89.66 \%$ & $(77.72 \%: 95.56 \%)$ \\
\hline Diagnostic accuracy & $77.50 \%$ & $(61.55 \%: 89.16 \%)$ \\
\hline
\end{tabular}

\section{DISCUSSION}

Intrauterine growth restriction (IUGR) is a common complication of pregnancy in developing countries which is associated with a high risk of perinatal mortality and morbidity. IUGR is the second leading cause of perinatal morbidity and mortality, after prematurity. IUGR is the condition in which the fetus is smaller or less developed than normal for the baby's gender and gestational age. Gestational age is the age of a fetus or baby that starts on the first day of the mother's last menstrual period ${ }^{(5)}$.

The fetal cerebro-placental ratio (CPR) is the ratio of the Middle Cerebral Artery Pulsatility Index (MCA PI) to the Umbilical Artery Pulsatility Index (UA PI). Normally, CPR gradually rises until around the 34th week and then it slowly declines until term. In some term SGA fetuses, the MCA PI is reduced despite normal UA Doppler indices (ie, a low CPR) and this is associated with poorer perinatal outcomes and adverse neurobehaviour sequelae ${ }^{(6)}$. And several studies have illustrated the utilization of CPR in the prediction of fetal compromise in labor (7) and neonatal unit admission ${ }^{(8)}$, a prediction of adverse perinatal outcome (9) as well as evaluation of fetal well-being in SGA fetuses ${ }^{(\mathbf{1 0})}$.

This study revealed that the residence was rural in $52.5 \%$ of cases and urban in $47.5 \%$ of cases, $67.5 \%$ of cases were multigravida and $32.5 \%$ of them were primigravida; $60 \%$ of them delivered by CS, of which the CS was elective in $79.17 \%$ of cases and was urgent in $20.83 \%$ of cases whereas $40 \%$ of them delivered normally.

The current study revealed that the mean UAD PI was normal in $50 \%$ of cases and abnormal in the other $502 \%$. Meanwhile, the mean MCD PI was abnormal in $52.5 \%$ of cases and normal in $47.5 \%$ of cases. Furthermore, the mean CPR was normal in $72.5 \%$ of cases and abnormal in $27.5 \%$ of cases.

The present study revealed that fetal weight was $57.5 \%$ of cases below the 10th centile and $42.5 \%$ of them were below the 5th centile. Apgar score was normal in $87.5 \%$ of cases and it was less than 7 in $12.5 \%$ of cases. Neonatal outcome within 1 month was: $80 \%$ of neonates were normal, $5 \%$ of them died, $7.5 \%$ of them were NICU admitted for more than 10 days and another
$7.5 \%$ of them were NICU admitted for more than 24 days.

The current study showed that changes in maternal age, residence, medical history, or parity were not associated with statistically significant changes in neonatal outcomes. On the other hand, changes in gestational age were associated with statistically significant changes in neonatal outcomes with older age being associated with normal outcomes. Furthermore, changes in the mode of delivery were associated with very highly statistically significant changes in neonatal outcome with $100 \%$ of normal deliveries being associated with normal neonatal outcome and $15.79 \%$ of elective CS and 100\% of urgent CS deliveries being associated with abnormal neonatal outcome. Changes in CPR were associated with statistically significant changes in neonatal outcome with higher CPR being associated with normal outcome and abnormality in CPR was associated with a statistically significant abnormality in the outcome as $89.66 \%$ of those with normal CPR and $54.55 \%$ of those with abnormal CPR had normal outcome, whereas $10.34 \%$ of those with normal CPR and $45.45 \%$ of those with abnormal CPR had an abnormal neonatal outcome.

The current study revealed that the sensitivity and specificity of UA Doppler indices in predicting neonatal outcomes are $62.5 \%$ and $53.12 \%$ respectively with a diagnostic accuracy of $55 \%$. The sensitivity and specificity of MCA Doppler indices in predicting neonatal outcomes were higher as they were $100 \%$ and $59.38 \%$ respectively with higher diagnostic accuracy of $67.5 \%$.

The present study also revealed that the sensitivity and specificity of CPR in predicting neonatal outcomes are $62.5 \%$ and $81.25 \%$ respectively with a diagnostic accuracy of $77.5 \%$. So CPR has a higher specificity and diagnostic accuracy when compared with UA and MCA Doppler indices as predictors of the neonatal outcome.

Similarly, Singh et al. ${ }^{(11)}$ reported that CPR had the highest diagnostic accuracy in prediction of adverse in clinically suspected IUGR cases when compared with $\mathrm{UA}$ and MCA indices.

Our study results demonstrated that the diagnostic performance of CPR value below 1.08 measured at 3437 weeks' gestation is superior to either MCA-PI or 
UA-PI alone in predicting adverse intrapartum and neonatal outcomes, including the need for urgent CS due to IFC, low fetal weight, 5-minute Apgar score $\leq 7$, NICU admission, and neonatal death. Therefore, CPR should be integrated into the assessment of pregnancies with FGR to identify high-risk cases that may benefit from certain timely intervention.

A recent meta-analysis showed that CPR has a moderate-to-high predictive ability for perinatal death with overall sensitivity and specificity of $93 \%$ and $76 \%$, respectively ${ }^{(3)}$.

Our study revealed a high diagnostic performance of CPR in predicting a 5-minute Apgar score below 7 with sensitivity and specificity of $100 \%$ and $85.37 \%$, respectively. However, Conde-Agudelo et al. (3) revealed a lower predictive performance with sensitivity and specificity of 54\% and $72 \%$, respectively.

On the other side, the sensitivity and specificity of CPR in predicting NICU admission were comparable in our study (50\% and 81.3\%) and Conde-Agudelo et al. (3) $(45 \%$ and $79 \%)$.

The association between abnormal CPR and adverse intrapartum and neonatal outcomes in pregnancies with FGR has been reported by several studies. However, the predictive accuracy of CPR varies among different outcomes as well as among various studies ${ }^{\mathbf{1 2} 2}$.

The present study revealed that CPR outperformed UA-PI and MCA-PI in predicting adverse neonatal outcomes.

\section{CONCLUSION}

CPR was more effective, with higher specificity and diagnostic accuracy, in predicting perinatal outcomes compared with the individual Doppler parameters of MCA and UA.

\section{REFERENCES}

1. Karlsen H, Ebbing C, Rasmussen S (2016): Use of conditional centiles of middle cerebral artery pulsatility index and cerebroplacental ratio in the prediction of adverse perinatal outcomes. Acta Obstet Gynecol Scand., 95:690-696.

2. Bakalis S, Peeva G, Gonzalez R (2015): Prediction of small-for-gestational-age neonates: screening by biophysical and biochemical markers at 30-34 weeks.
Ultrasound Obstet Gynecol., 46:446-451.

3. Conde-Agudelo A, Villar J, Kennedy S et al. (2018): Predictive accuracy of cerebroplacental ratio for adverse perinatal and neurodevelopmental outcomes in suspected fetal growth restriction: systematic review and metaanalysis. Ultrasound Obstet Gynecol., 52(4): 430-441.

4. Vollgraff Heidweiller-Schreurs C, De Boer $M$, Heymans M et al. (2018): Prognostic accuracy of cerebroplacental ratio and middle cerebral artery Doppler for the adverse perinatal outcome: systematic review and meta-analysis. Ultrasound Obstet Gynecol., 51(3): 313322.

5. American International Medical University (2018): Intrauterine growth restriction (IUGR): Symptoms, causes, diagnosis, management, complications \& prevention.

https://www.aimu.us/2018/01/15/intrauterine-growthrestriction-iugr-symptoms-causes-diagnosismanagement-complications-prevention/

6. Sherrell H, Clifton V, and Kumar S (2018): Predicting intrapartum fetal compromise at term using the cerebroplacental ratio and placental growth factor levels (PROMISE) study: Randomised controlled trial protocol. BMJ Open, 8:e022567.

7. Prior T, Mullins E, Bennett $P$ et al. (2014): Prediction of fetal compromise in labor. Obstet Gynecol., 123(6): $1263-71$.

8. Khalil A, Morales-Rosello J, Morlando $\mathrm{M}$ et al. (2015): Is fetal cerebroplacental ratio an independent predictor of intrapartum fetal compromise and neonatal unit admission? Am J Obstet Gynecol., 213(1):1-10.

9. Dunn L, Sherrell $H$ and Kumar S (2017): Review: Systematic review of the utility of the fetal cerebroplacental ratio measured at term for the prediction of adverse perinatal outcome. Placenta, 54:68-75.

10. Devore G (2015): The importance of the cerebroplacental ratio in the evaluation of fetal wellbeing in SGA and AGA fetuses. Am J Obstet Gynecol., 213(1):5-15.

11. Singh G, Gupta N, Singhal S et al. (2018): Correlation of efficacy of cerebro placental ratio with adverse perinatal outcome in clinically suspected IUGR pregnancies. Int J Reprod Contracept Obstet Gynecol., 7(5):1808-12.

12. Nassr A, Abdelmagied A, Shazly S (2016). Fetal cerebro-placental ratio and adverse perinatal outcome: systematic review and meta-analysis of the association and diagnostic performance. J Perinat Med., 44(2):249256. 